\title{
RELATIVE FREQUENCY OF CONGENITAL HEART DISEASES IN BABIES WITH CLEFT LIP AND/OR PALATE
}

\author{
Ravikumar P1, Mohammed Manekkat Thekke Peedikayil2, Tradib Arekanadth Jayapal ${ }^{3}$ \\ ${ }^{1}$ Senior Lecturer, Department of Paediatrics, Pariyaram Medical College, Kannur, Kerala. \\ 2Professor, Department of Paediatrics, Pariyaram Medical College, Kannur, Kerala. \\ 3Associate Professor, Department of Orthodontics, Pariyaram Dental College, Kannur, Kerala.
}

\begin{abstract}
Orofacial clefts are among the most common congenital anomalies. A significant number of patients with cleft palate have other associated malformations that may result in cardiac, limb or other system defects. Establishing a significant relationship of associated anomalies in cleft lip and cleft palate is important for several reasons. Firstly, this will improve screening and evaluation methods in departments dealing with cleft lip and palate and other craniofacial anomalies because of increased vigilance on the part of health care providers. Secondly, it will help provide optimal and comprehensive care, clear identification of problems will be made possible, proper consultations obtained and appropriate measures taken to manage the patient. Finally, corroboration of cleft lip and cleft palate with associated congenital anomalies may lead to a greater understanding of the embryonic phenomena underlying the malformation process in the future. This study assesses frequency of associated malformations in babies with cleft lip/palate. Babies with cleft lip/palate are prospectively enrolled in the study and analysed for occurrence of associated malformations. The relative frequency of congenital heart diseases is significantly high $(30.2 \%$ of the study group and it accounts for $69.5 \%$ of the associated anomalies). Hence, routine echocardiography of these babies is recommended for early diagnosis and appropriate care.
\end{abstract}

\section{KEYWORDS}

Cleft Lip and Palate, Echocardiography, Congenital Heart Diseases.

HOW TO CITE THIS ARTICLE: Ravikumar P, Peedikayil MMT, Jayapal TA. Relative frequency of congenital heart diseases in babies with cleft lip and/or palate. J. Evolution Med. Dent. Sci. 2016;5(23):1258-1260, DOI: 10.14260/jemds/2016/293

\section{INTRODUCTION}

There is increased frequency of other associated malformations in babies with cleft lip and palate. Congenital heart diseases have been reported in 1.3 to $27 \%$ of patients with oral cleft. ${ }^{1}$ Association of cleft lip and palate and other congenital malformations has a documented incidence, varying from $1.5 \%$ to $63.4 \% .2,3$

\section{OBJECTIVES}

1. To assess the relative frequency of associated malformations, particularly Congenital Heart Diseases in babies under 2 years of age with cleft lip and/or palate referred to the Cleft Palate Clinic and Paediatric Outpatient Clinic of a Teaching Hospital.

2. Comparing our data with that of world literature.

There is a great paucity of literature on the associated malformations in cleft children from this region of the Indian subcontinent. It has not yet been established whether clefts of the face are conclusively related to the specific types of other congenital defects it has been found to be associated with. There are differences of opinion with regards to which organ system is most often affected by associated malformations in cleft lip and cleft palate patients. Therefore, this study looks into the clinical profile of cleft lip/palate and its association with other congenital malformations.

Financial or Other, Competing Interest: None.

Submission 03-02-2016, Peer Review 02-03-2016,

Acceptance 07-03-2016, Published 21-03-2016.

Corresponding Author:

Dr. Ravikumar Payora

Senior Lecturer,

Department of Paediatrics,

Pariyaram Medical College,

Kannur-670503,

Kerala State, India.

E-mail:drrvkmr@gmail.com

DOI: $10.14260 /$ jemds/2016/293
Incidence of facial clefts is quoted at upto 2 per 1000 live births. ${ }^{4}$ and has been found to be rising. Bailey and Love's 'Short Practice of Surgery' quotes the incidence of cleft lip and palate as 1 in 600 live births and of isolated palate is 1 in 1000 live births. 5

\section{MATERIALS AND METHODS}

This prospective observational hospital-based case study has been conducted at the Cleft Palate Clinic, Department of Orthodontics and OP Clinic of Department of Paediatrics at a tertiary care teaching hospital. The duration of this study was two years from March 2011 to February 2013.

\section{Study Design}

All babies less than two years of age with cleft palate and/or cleft lip presented to or referred to the Cleft Palate Clinic and Paediatric OPD are prospectively enrolled in the study group. The sampling technique used in this study is sequential sampling. This method consists of a sequence of samples drawn one after another from the study population. All cases taken in the study are evaluated according to a preformed proforma. Relevant information regarding family history, community, sex, birth weight and feeding history are documented. Antenatal USG findings are recorded.

All babies undergo a thorough clinical examination. Laboratory investigations and specialist consultations are done at the discretion of the team of doctors treating that particular case. Those babies with clinical examination suggestive of congenital heart diseases are subjected to echocardiography to detect congenital heart disease. An abdominal USG is obtained in indicated cases to rule out renal anomalies. The clinical profile of these babies evaluated and prevalence rates of different malformations are determined. 
A simple Descriptive Classification was used to Record the Cleft type as follows:

1. Babies with cleft lip alone.

2. Babies with cleft palate alone.

3. Babies with cleft palate and cleft lip.

Clinical profile and prevalence of anomalies, especially congenital heart disease in each group are evaluated and compared.

\section{RESULTS}

In this study the most common associated malformation was found to be congenital heart disease, which accounted for $69.5 \%$ of all associated malformations. Renal anomalies accounted for $17.3 \%$ of associated anomalies. Skeletal anomalies form $13 \%$ of all anomalies. Other facial anomalies (Other than clefts) and retrognathia constitute $8.6 \%$ each. Isolated congenital heart disease is seen in 9 cases, which constitute $39 \%$ of the anomalies. Data were analysed by plotting in frequency distribution tables prepared using SPSS (Statistical Package for the Social Sciences) version 20; 30.2\% of the study group is found to have congenital heart disease. The prevalence of associated congenital heart diseases was $35.1 \%$ in those with cleft lip and palate, $20 \%$ for isolated cleft palate and $18.2 \%$ for isolated cleft lip.

\begin{tabular}{|c|c|c|c|}
\hline Type of Cleft & \multicolumn{2}{|r|}{ CHD } & Total \\
\hline & No CHD & CHD Present & \\
\hline Cleft Lip only & 9 & 2 & 11 \\
\hline Cleft Lip \& Palate & 24 & 13 & 37 \\
\hline Cleft Palate only & 4 & 1 & 5 \\
\hline Total & 37 & 16 & 53 \\
\hline Percentage & 69.2 & 30.2 & 100 \\
\hline
\end{tabular}

CHD: Congenital Heart Disease.

\begin{tabular}{|c|c|c|c|}
\hline Study & CL & CP & CLP \\
\hline Present study & $18.2 \%$ & $60 \%$ & $48.6 \%$ \\
\hline C. Stoll. 6 & $13.6 \%$ & $46.7 \%$ & $36.8 \%$ \\
\hline Milerad J.7 & $8 \%$ & $22 \%$ & $28 \%$ \\
\hline \multicolumn{3}{|c|}{ Table 2: Presence of associated Congenital } \\
Malformations in different types of clefts \\
as reported by different studies \\
\hline
\end{tabular}

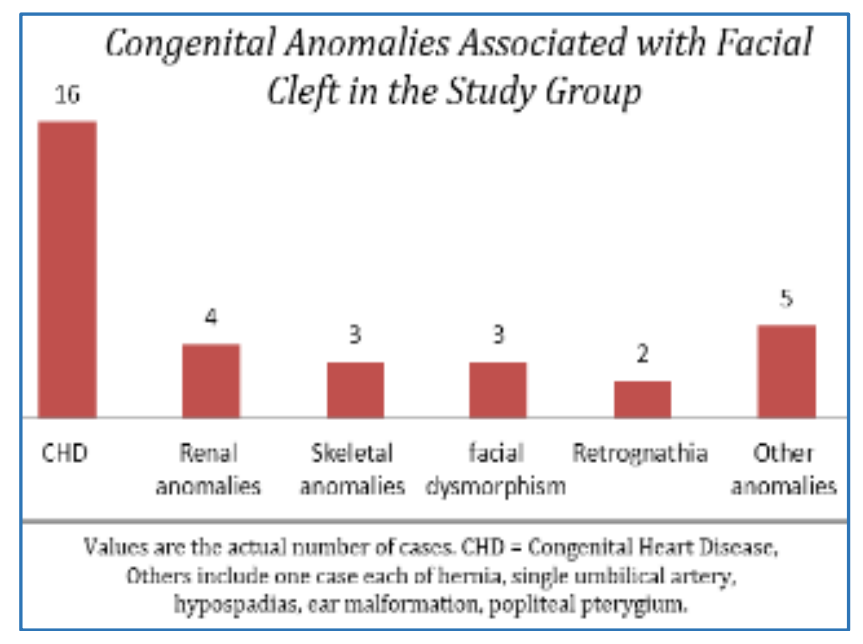

Fig. 1: Other Congenital Anomalies associated with Facial Cleft

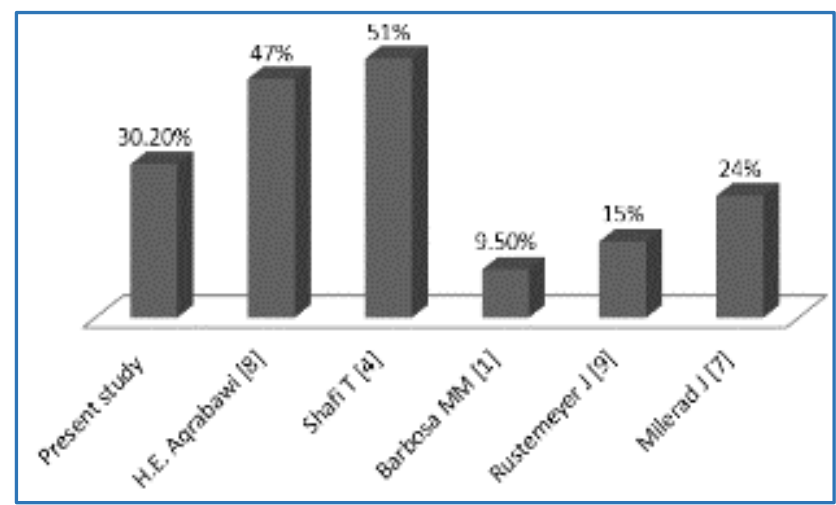

Fig. 2: Relative Frequency of CHD reported in Different Studies

\section{DISCUSSION}

In this study, a total of 53 babies with facial cleft were examined; 23 babies have other congenital anomalies; 16 babies have congenital heart diseases. The observed relative frequency of $43.4 \%$ of associated congenital malformations among babies with facial cleft highlights the magnitude of the problem. The presence of facial cleft in a child should raise the suspicion of an associated anomaly. The likelihood of this being a cardiac defect is high. The high relative frequency of congenital heart disease (30.2\% of the study group) may justify a routine echocardiographic screening. This study may be useful to make the awareness about the magnitude of associated congenital malformations in babies with cleft lip/palate.

Prevalence of associated congenital anomalies in different types of cleft.

The present study shows $60 \%$ of babies with isolate cleft palate has associated anomalies, $48.6 \%$ of babies with cleft lip and palate had associated anomalies, whereas in babies with isolated cleft lip the prevalence of other congenital anomalies was $18.2 \%$. A study by Stoll C. 6 reported $46.7 \%$ of babies with isolated cleft palate had associated anomalies, $36.8 \%$ of babies with cleft lip and palate had associated anomalies and 13.6\% of babies with isolated cleft lip had other anomalies. Another study by Milerad J.7 shows $22 \%$ of cleft palate babies had associated anomalies, $28 \%$ of babies with cleft lip and palate had associated anomalies and 8\% of isolated cleft lips had other associated anomalies.

\section{Relative Frequency of CHD in Babies with Facial Cleft}

In the present study, $30.2 \%$ of the study group is found to have congenital heart disease. A study by H. E. Aqrabawi. ${ }^{8}$ reported that $47 \%$ of babies with facial cleft had CHD. Another study by T. Shafi. ${ }^{4}$ shows $51 \%$ of babies with facial cleft had CHD, whereas studies by M. M. Barbosa. ${ }^{1}$ Rusytemayer. ${ }^{9}$ and Milerad J. ${ }^{7}$ reported the relative frequency of CHD in babies with facial cleft as $9.5 \%, 15 \%$ and $24 \%$ respectively.

2600 cleft patients were analysed in a study from the cleft and craniofacial centre of Sri Ramachandra University of the 2600 patients, 198 had associated anomalies, of these 33 had cardiac anomalies. ${ }^{10}$ In another Indian study by P. S. Shekon showed the relative frequency of CHD in babies with facial cleft as $10 \% .11$

Twenty-six CHDs were diagnosed in 16 of 53 patients (30.2\%): 5 Atrial Septal Defects, 9 Ventricular Septal Defects, 8 Patent Ductus Arteriosus, 2 Persistent Foramen Ovale, 1 Pulmonary Stenosis and 1 Single Ventricle. 


\section{CONCLUSION AND RECOMMENDATIONS}

1. Increased risk of associated malformations in children with clefts must be highlighted and disseminated to health professionals involved in the management of children with clefts.

2. The high prevalence of malformations in cleft infants emphasizes the need for a thorough investigation of these infants; routine echocardiography screening for cardiac malformations may need to be considered in view of high relative frequency of congenital heart disease among these babies.

3. This study stresses the need for more hospital based as well as community based studies to estimate the prevalence of associated congenital malformations in babies with facial clefts.

\section{REFERENCES}

1. Barbosa MM, Rocha CMG, Katina T, et al. Prevalence of congenital heart diseases in oral cleft patients. Pediatr Cardiol 2003;24:369-374.

2. Yi NN, Yeow VK, Lee ST. "Epidemiology of cleft lip and palate in Singapore a 10-year hospital-based study. Ann Acad Med Singapore 1999;28:655-659.

3. Shprintzen RJ, Siegel-Sadewitz VL, Amato J, et al. "Anomalies associated with cleft lip, cleft palate, or both." Am J Med Genetics 1985;20:585-595.
4. Shafi T, Khan MR, Atiq M. "Congenital heart disease and associated malformations in children with cleft lip and palate in Pakistan." Br J of Plastic Surg 2003;56:106-109.

5. Williams P Smith. Cleft lip and palate: developmental abnormalities of the face, mouth and jaws. In: Norman $\mathrm{S}$ Williams, Christopher JK, Bulstrode, eds. Baily and love's short practice of surgery. CRC Press Tayler and Francis Group. 2013;26 th edition:p 634.

6. Stoll C, Alembik Y, Dott B, et al. Associated malformations in cases with oral clefts. cleft palate craniofacial Journal 2000;37(1):41-7.

7. Milerad J, Larson O, Hagberg C, et al. "Associated malformations in infants with cleft lip and palate: a prospective, population-based study." Pediatrics 1997;100(2):180-186.

8. Aqrabawi HE. Facial cleft and associated anomalies: incidence among infants at a Jordanian medical centre. Eastern Mediterranean Health Journal 2008;14(2):356-9.

9. Rustemeyer J, Gunther L, Krause HR, et al. "Associated anomalies in lip-maxillopalatal clefts." Mund Kiefer Gesichtschir 2000;4(5):274-277.

10. Venkatesh R. Syndromes and anomalies associated with cleft. Indian J Plast Surg 2009;42(Suppl):S51-S55.

11. Sekhon PS, Ethunandan M, Markus AF, et al. Congenital anomalies associated with cleft lip and palate-an analysis of 1623 consecutive patients. Cleft Palate Craniofacial Journal 2011;48(4):371-8. 